\title{
APLIKASI PELAPORAN KEGIATAN MENTORING DI UNIVERSITAS TEKNOLOGI SUMBAWA BERBASIS ANDROID
}

\author{
Nawassyarif ${ }^{1 *}$, Yahya Abdan Syakura² ${ }^{2}$ Nurlaily $^{3}$ \\ ${ }^{1.3}$ Dosen Informatika Universitas Teknologi Sumbawa \\ ${ }^{2}$ Mahasiswa Informatika Universitas Teknologi Sumbawa \\ Email : nawassyarif@uts.ac.id ${ }^{1}$, yahyaaabdan@ gmail.com ${ }^{2}$, nurlaily@uts.ac.id ${ }^{3)}$
}

\begin{abstract}
Abstrak
Universitas Teknologi Sumbawa (UTS) merupakan salah satu Perguruan Tinggi Swasta yang ada di Kabupaten Sumbawa Provinsi Nusa Tenggara Barat. Unit Mentoring adalah salah satu organisasi yang terdapat di Universitas Teknologi Sumbawa. Penelitian ini bertujuan untuk membangun aplikasi pelaporan kegiatan mentoring berbasis android yang dapat digunakan untuk membantu proses pelaporan kegiatan mentoring yang dimana mencakup absensi, penilaian tilawah, penilaian ujian, serta memudahkan pengurus dalam mengelola kegiatan agar dapat berjalan dengan baik. Maka perlu dibangun sebuah aplikasi berbasis android serta dikembangkan menggunakan Android Studio dengan menggunakan MySql sebagai database dan sublime text sebagai text editor. Metode pengembangan perangkat lunak menggunakan Waterfall Model dan Pengujian perangkat lunak dilakukan melalui pengujian black-box.Teknik pengumpulan data pada penelitian menggunakan wawancara dan dokumentasi., Hasil penelitian berguna untuk membantu pengajar dalam proses absensi kegiatan mentoring serta pengurus dalam mengelola kegiatan agar dapat berjalan dengan baik.
\end{abstract}

Kata kunci: Unit Mentoring, Aplikasi, Pelaporan Kegiatan Mentoring, Waterfall, Android Studio

\begin{abstract}
Sumbawa University of Technology (UTS) is a private university in the Sumbawa Regency, West Nusa Tenggara Province. The Mentoring Unit is one of the organizations located at the Sumbawa University of Technology. This research aims to build an Android-based mentoring activity reporting application that can be used to assist the reporting process of mentoring activities which includes attendance, recitation assessment, and examination evaluation, and also administrators in managing activities so that they can run well. Researchers built an Androidbased application and developed it using Android Studio by using MySql as a database and sublime text as a text editor. Software development method uses Waterfall Model and software testing is done through black-box testing. Data collection techniques in research using interviews and documentation, the results of this study are web-based thesis registration applications that are useful to assist teachers in the process of mentoring and management in managing activities in order to run well.
\end{abstract}

Keyword: Mentoring Unit, Application, Reporting Mentoring Activities, Waterfall, Android Studio

\section{PENDAHULUAN}

\section{Latar Belakang}

Kegiatan mentoring saat ini belum memiliki sistem pelaporan kegiatan setiap minggu bagi para peserta dan pengajar yang akan digunakan untuk kegiatan evaluasi beasiswa. Dalam sistem pelaporan tersebut terdapat beberapa macam kriteria pelaporan, yaitu absensi mingguan, penilaian membaca Al-Qur'an, dan penilaian ujian. Sistem yang sedang berjalan saat ini yaitu para pengajar masih menginput data-data para peserta, absensi, penilaia membaca Al-Qur'an dan penilaian ujian secara manual menggunakan buku.

Maka atas dasar tersebut, demi mempermudah proses kegiatan mentoring, diperlukan suatu sistem pelaporan kegiatan mentoring yang lebih efisien dan dapat meminimalisir waktu yang digunakan dalam melakukan proses pelaporan kegiatan mentoring. Sistem pelaporan ini, akan dibangun dengan teknologi berbasis android agar dapat melayani proses pelaporan kegiatan mentoring secara online. Pemilihan teknologi berbasis android dikarenakan dapat di akses melalui smartphone dengan internet dan dapat di akses kapanpun dan dimanapun.

Diharapkan dengan adanya penelitian ini dapat membantu merancang suatu sistem pelaporan kegiatan pada unit mentoring berbasis android. Dan juga diharapkan dapat mempermudah pengajar dalam melakukan proses pelaporan kegiatan mentoring.

\section{Rumusan Masalah}

Adapun rumusan masalah penelitian ini adalah "Bagaimana merancang dan membangun suatu aplikasi pelaporan kegiatan berbasis android agar dapat membantu para pengajar dalam 
melakukan proses pelaporan kegiatan yang belum terkomputerisasi?“.

\section{Batasan Masalah}

Adapun batasan masalah dalam penelitian ini adalah sebagai berikut:

1. Penelitian di lakukan pada Unit Mentoring.

2. Sumber data di peroleh dari Unit Mentoring.

3. Aplikasi pendaftaran skripsi ini berbasis android.

\section{Tujuan Penelitian}

Tujuan penelitian adalah untuk merancang suatu sistem pelaporan kegiatan mentoring berbasis android secara online pada Unit Mentoring agar dapat mempermudah para pengajar dalam melakukan proses pelaporan kegiatan mentoring maupun pengurus dalam mengelola kegiatan agar dapat berjalan dengan baik.

\section{Manfaat Penelitian}

Manfaat penelitian yang di dapatkan, mencakup manfaat bagi penulis; manfaat bagi Program Studi Informatika; dan manfaat bagi civitas akademika.

a. Bagi Penulis.

1. Dapat mengimplementasikan ilmu-ilmu yang diperoleh selama masa perkuliahan.

2. Dapat merancang aplikasi pelaporan kegiatan mentoring berbasis android pada Unit Mentoring.

3. Sebagai salah satu syarat untuk menyelesaikan mata kuliah Skripsi Semester VIII (delapan) Program Studi Informatika, Fakultas Teknik, Universitas Teknologi Sumbawa.

b. Bagi Unit Kegiatan Mentoring

1. Membantu ketua kegiatan mentoring dalam pelaporan kegiatan.

2. Membantu pengurus kegiatan mentoring dalam mengatur jalannya kegiatan mentoring di setiap kelompok.

3. Membantu Pengajar dalam melakukan proses pelaporan kegiatan mentoring.

c. Bagi Pembaca

1. Untuk dijadikan informasi atau pembanding dengan gagasan dan ide yang sama.

2. Dapat menjadi referensi bagi para pembaca untuk membuat karya ilmiah di kemudian hari.

\section{Sistematika Penulisan}

Untuk memberi gambaran tentang penelitian ini, maka disusunlah suatu sistematika penulisan berisi tentang materi yang dibahas disetiap bab pembahasan.

\section{LANDASAN TEORI}

\section{Tinjauan Pustaka}

Dalam penulisan skripsi ini penulis mencari penelitian-penelitian sebelumnya sebagai bahan pembanding, baik mengenai kekurangan atau kelebihan yang berkaitan dengan judul yang akan digunakan.

Penelitian pertama adalah penelitian yang berjudul "Perancangan Aplikasi Pelaporan Kerusakan Prasarana Berbasis Android Menggunakan Google Cloud Messaging (GCM)". Dalam tugas akhir tersebut dibangun sebuah aplikasi pelaporan kerusakan prasarana yang memanfaatkan teknologi Google Cloud Messaging untuk mendapatkan pesan dan layanan pemberitahuan android [1].

Kemudian penelitian kedua adalah penelitian yang berjudul "Aplikasi Pelaporan Data Siswa Berbasis Web". Dalam tugas akhir tersebut dibangun sebuah sistem pelaporan data siswa dengan memanfaatkan konsep teknologi web agar dapat melayani proses pengajuan judul skripsi secara online [2].

Selanjutnya penelitian ketiga adalah penelitian yang bejudul "Aplikasi Pelaporan Kerusakan Jalan Tol Menggunakan Layanan Web Service Berbasis Android'. Dalam tugas akhir tersebut dibangun sebuah aplikasi pelaporan kerusakan jalan tol yang memanfaatkan Web Service untuk memanfaatkan efisiensi waktu dalam pelaporan kerusakan jalan tol [3]

Demikian hasil penelitian sebelumnya yang penulis temukan, karena terdapat judul serta permasalahan yang mempunyai kesamaan dengan penelitian yang dilakukan penulis, walaupun demikian dalam penelitian yang penulis lakukan terdapat beberapa perbedaan yaitu lokasi penelitian, data penelitian, platform yang digunakan serta perancangan sistem yang berbeda dari penelitian sebelumnya.

\section{Dasar Teori}

Adapun dasar teori yang mendukung dalam pembuatan laporan ini sebagai berikut:

\section{Aplikasi}

Perangkat lunak aplikasi adalah suatu subkelas perangkat lunak komputer yang memanfaatkan kemampuan komputer langsung 
untuk melakukan suatu tugas yang diinginkan pengguna [4].

Berdasarkan pernyataan di atas penulis dapat mengambil kesimpulan bahwa aplikasi adalah suatu subkelas perangkat lunak yang dibuat untuk melayani kebutuhan penggunanya.

\section{Unified Modeling Language (UML)}

Unified Modeling Language (UML) adalah pemodelan yang digunakan oleh developer untuk berkomunikasi mengenai pekerjaan mereka dengan para stakeholder dan developer yang lain [5].

Adapun jenis-jenis Unified Modeling

Language (UML) adalah sebagai berikut :

\section{Use Case Diagram}

Diagram Use Case yang digunakan untuk menganalisis interaksi yang di sediakan pada antar muka aplikasi yang menggambarkan subuah interaksi sistem dan aktor.

\section{Activity Diagram}

Activity diagram merupakan pemodelan yang dari seluruh proses yang terjadi pada sistem.

\section{Squence Diagram}

Sequence diagram yang merupakan diagram yang mejelaskan interaksi pada objek berdasarkan urutan waktu. Sequence diagram memeliki fokus pada perilaku didalam sistem mengilustrasikan bagaimana objek dan pesan yang dikirim antar projek.

\section{Class Diagram}

Class diagram adalah diagram yang akan digunakan untuk menampilkan kelaskelas atau paket-paket pada sistem yang akan digunakan

\section{Waterfall}

Model waterfall memiliki tahapan utama dari waterfall model yang mencerminkan aktifitas pengembangan dasar. Terdapat 5 (lima) tahapan pada metode waterfall, yaitu requirement analysis and definition, system and software design, implementation and unit testing, integration and system testing, dan operation and maintenance [6].

\section{Pengujian Perangkat Lunak}

Pengujian perangkat lunak adalah elemen kritis dari jaminan kualitas perangkat lunak dan mempersentasikan kajian pokok dari spesifikasi, desain, dan pengkodean [7].
Dalam pengujian perangkat lunak, penulis membandingkan dua jenis metode pengujian yaitu Black Box dan White Box.

Tabel 1. Perbandingan Pengujian Black box dengan White box

\begin{tabular}{|c|c|c|}
\hline No & \multicolumn{2}{|c|}{ Metode Perangkat } \\
\hline 1 & \multicolumn{2}{|r|}{ Blcak Box } \\
\hline & Pengertian & $\begin{array}{l}\text { Pengujian yang didasarkan } \\
\text { pada detail aplikasi seperti } \\
\text { tampilan aplikasi, fungsi- } \\
\text { fungsi yang ada pada } \\
\text { aplikasi, dan kesesuaian alur } \\
\text { fungsi dengan bisnis proses } \\
\text { yang diinginkan oleh } \\
\text { customer. }\end{array}$ \\
\hline & $\begin{array}{l}\text { Kegiatan } \\
\text { Pengujian }\end{array}$ & $\begin{array}{llr}\text { a. } & \text { Membuat test case } \\
\text { untuk menguji fungsi- } \\
\text { fungsi yang ada pada } \\
\text { aplikasi } \\
\text { b. Membuat test case } \\
\text { untuk r menguji } \\
\text { kesesuaian alur kerja } \\
\text { suatu fungsi di aplikasi } \\
\text { dengan requirement } \\
\text { yang dibutuhkan } \\
\text { customer }\end{array}$ \\
\hline \multirow[t]{3}{*}{2} & \multicolumn{2}{|r|}{ White Box } \\
\hline & Pengertian & $\begin{array}{l}\text { Pengujian yang didasarkan } \\
\text { pada detail prosedur dan alur } \\
\text { logika kode program. Pada } \\
\text { kegiatan whitebox testing, } \\
\text { tester melihat source code } \\
\text { program dan menemukan } \\
\text { bugs dari kode program yang } \\
\text { diuji. Intinya whitebox } \\
\text { testing adalah pengujian yang } \\
\text { dilakukan sampai kepada } \\
\text { detail pengecekan kode } \\
\text { program. }\end{array}$ \\
\hline & $\begin{array}{l}\text { Kegiatan } \\
\text { Pengujian }\end{array}$ & $\begin{array}{l}\text { Melihat kode program } \\
\text { membuat test case untuk } \\
\text { mencari kesalahan atau bugs } \\
\text { atau error dari kode program } \\
\text { yang dibuat oleh programmer }\end{array}$ \\
\hline
\end{tabular}

\section{Android}

Android merupakan sistem operasi untuk telepon seluler yang berbasis Linux. Android menyediakan platform terbuka bagi para pengembang untuk menciptakan aplikasi mereka sendiri untuk digunakan oleh berbagai macam mobile device [8]. 


\section{Mentoring}

Mentoring merupakan hubungan interpersonal dalam bentuk kepedulian dan dukungan antara seseorang yang berpengalaman dan berpengetahuan luas dengan seseorang yang kurang berpengalaman maupun yang pengetahuannya lebih sedikit [9].

Penelitian

Penelitian adalah suatu kegiatan ilmiah yang terencana, terstruktur, sistematis dan memiliki tujuan tertentu baik praktis maupun teoritis [10].

Berdasarkan pernyataan dari para ahli penulis dapat mengambil kesimpulan bahwa penelitian adalah suatu proses bertahap yang terencana, terstruktur, dan sistematis yang dimulai dengan identifikasi masalah atau isu yang akan diteliti.

\section{METODOLOGI PENELITIAN}

\section{Metode Penelitian}

Tahap-tahap yang dilakukan dalam pengumpulan data untuk merancang dan membangun sistem informasi ini dapat digambarkan pada bagan alur sebagai berikut:

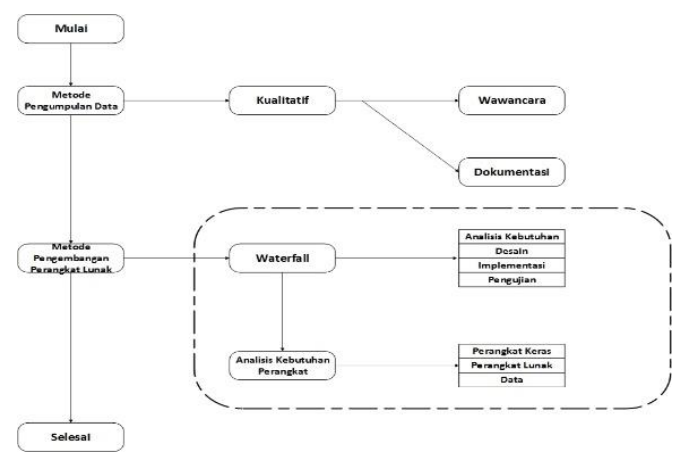

Gambar 1. Metode Penelitian

\section{Metode Pengumpulan Data}

Pada tahapan peneliti melakukan pengumpulan data dengan konsep deskriptif dan data kualitatif. Adapun langkah-langkah yang dilakukan adalah dengan menggunakan beberapa metode yaitu wawancara, dan dokumentasi.

a. Wawancara

Pada tahap ini peneliti melakukan wawancara dan tanya jawab dengan Bapak Iwan Wahyudi Selaku Ketua Unit Kegiatan Mentoring.

b. Dokumentasi

Tahap dokumentasi adalah tahapan dimana peneliti mengambil data berupa gambar atau foto dari dokumen maupun berkas-berkas yang terkait dengan penelitian, yaitu berkas kegiatan mentoring pada Unit Mentoring Universitas Teknologi Sumbawa.

\section{Metode Pengembangan Perangkat Lunak}

Berdasarkan perbandingan yang telah di jelaskan peneliti menyimpulkan metode waterfall sesuai dengan penelitian yang dilakukan, karena pengembangan perangkat lunak dilakukan secara bertahap sehingga teliti dalam merancang dan mengembangkan perangkat lunak.

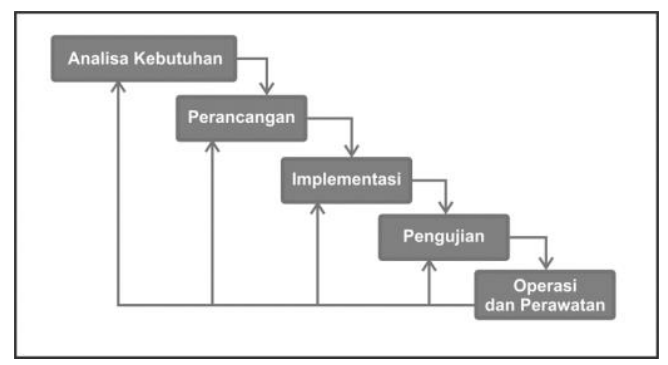

Gambar 2. Metode Waterfall

\section{Alat Dan Bahan Penelitian}

Alat penelitian yang digunakan dibagi menjadi tiga yaitu komponen perangkat keras, perangkat lunak, dan kebutuhan data sebagai pendukung penelitian yang dilakukan, alat ini yang akan dijadikan sebagai alat pengolahan data dan pembuatan sistem yang akan dirancang.

\section{HASIL DAN PEMBAHASAN}

\section{Analisa Program}

Berikut adalah hasil Analisa program yang telah penulis lakukan guna membantu dalam perancangan pada sistem pelaporan kegiatan mentoring di Universitas Teknologi Sumbawa:

Dibawah ini merupakan penjelasan prosedur sistem pelaporan kegiatan mentoring yang sedang berjalan saat ini pada Unit Mentoring Universitas Teknologi Sumbawa. 
Alur Sistem Pelaporan Kegiatan Mentoring Yang Sedang Berjalan

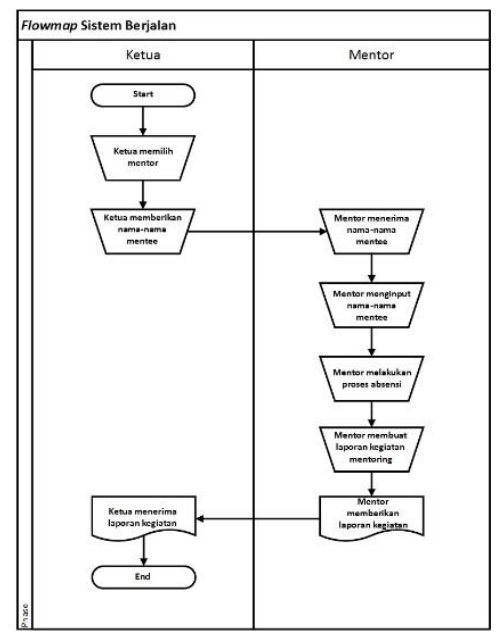

Gambar 3. Alur Sistem Pelaporan Kegiatan Mentoring Yang Sedang Berjalan

\section{Rancangan Sistem}

Berikut adalah rancangan sistem usulan yang akan dibuat untuk pelaporan kegiatan mentoring berbasis android pada Unit Mentoring Universitas Teknologi Sumbawa:

Rancangan sistem usulan disini, merupakan rancangan sistem untuk menggantikan sistem yang sedang berjalan untuk pelaporan kegiatan mentoring pada Unit Mentoring Universitas Teknologi Sumbawa. Berikut merupakan gambaran dari rancangan sistem yang diusulkan.

Alur Sistem Pelaporan Kegiatan Mentoring Yang Diusulkan

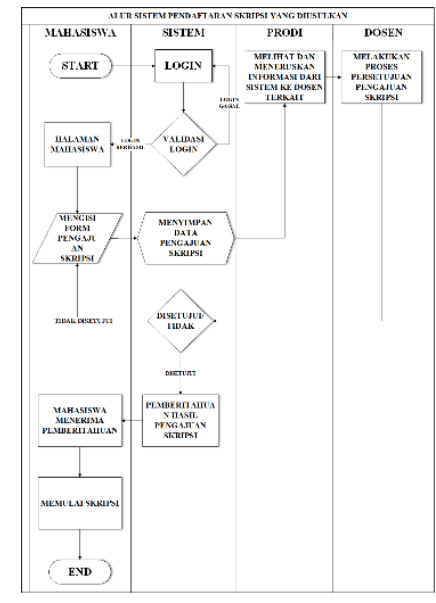

Gambar 4. Alur Sistem Pelaporan Kegiatan Mentoring Yang Diusulkan

\section{Unified Modeling Language (UML)}

Adapun Unified Modeling Language (UML) yang terdapat didalam pelaporan kegiatan mentoring berbasis android pada Unit Mentoring Universitas Teknologi Sumbawa terdiri dari Use Case Diagram, Activity Diagram, Sequence Diagram, dan Class Diagram.

\section{Use Case Diagram}

Use Case Diagram men-deskripsikan hubungan antara pengguna sistem (aktor) dengan aktivitas-aktivitas atau proses pada Aplikasi Pendaftaran Skripsi Berbasis Web di Program Studi Informatika. Pada aplikasi ini terdapat dua aktor, yakni Admin dan User. Untuk menjelaskan usecase diagram dari aplikasi yang akan di bangun dijelaskan pada usecase spesifikasi tiap aktor.

\section{Use case Diagram Admin}

Adapun perancangan use case diagram admin adalah sebagai berikut.

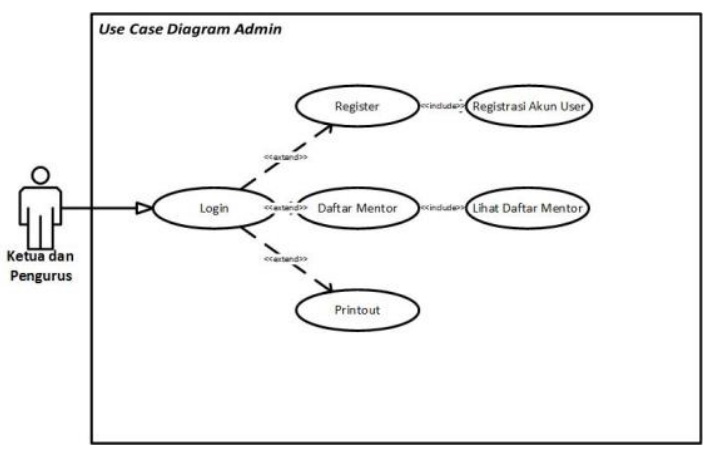

Gambar 5. Use case Diagram Admin

2. Use case Diagram User

Adapun perancangan use case diagram user adalah sebagai berikut :

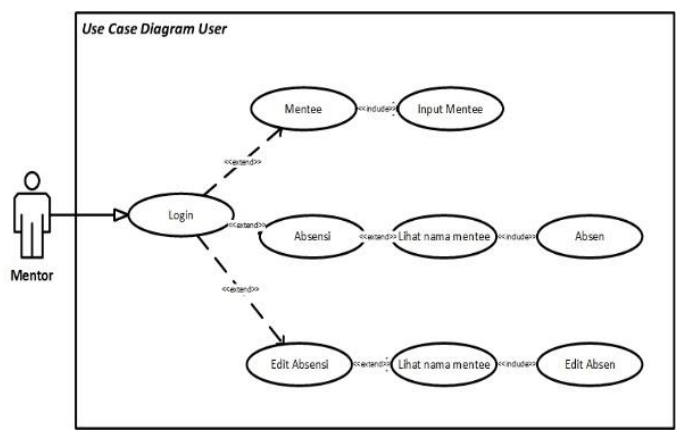

Gambar 6. Use case Diagram Mahasiswa

\section{Activity Diagram}

Activity diagram pada aplikasi ini dibagi menjadi dua bagian yaitu bagian admin, dan bagian user. Setiap bagian mempunyai beberapa activity diagram yang berfungsi untuk meng-gambarkan alur setiap fungsi yang ada didalam aplikasi, berikut dibawah ini adalah activity diagram pada Aplikasi Pelaporan Kegiatan Mentoring di Unversitas Teknologi Sumbawa Berbasis Android. 
1. Activity Diagram Daftar Mentor Admin Adapun perancangan activity diagram daftar mentor adalah sebagai berikut.

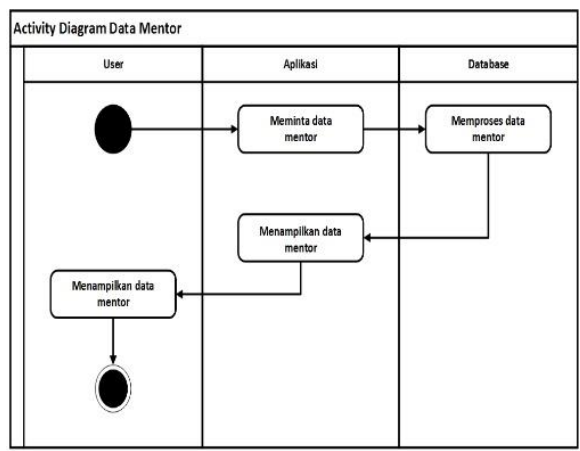

Gambar 7. Activity Diagram Daftar Mentor Admin

2. Activity Diagram Registrasi Admin Adapun perancangan activity diagram registrasi adalah sebagai berikut.

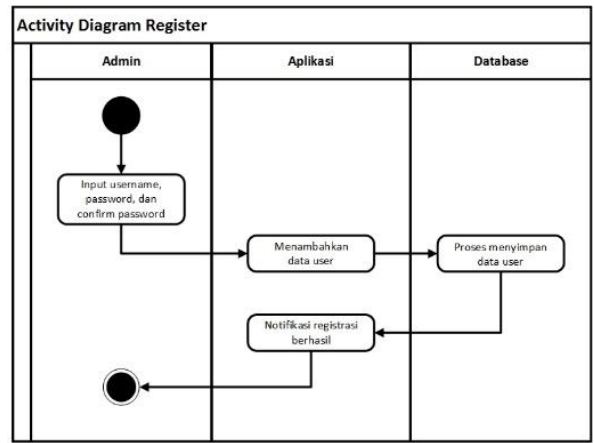

Gambar 8. Activity Diagram Registrasi Admin

\section{Activity Diagram Printout Admin}

Adapun perancangan activity diagram printout admin adalah sebagai berikut.

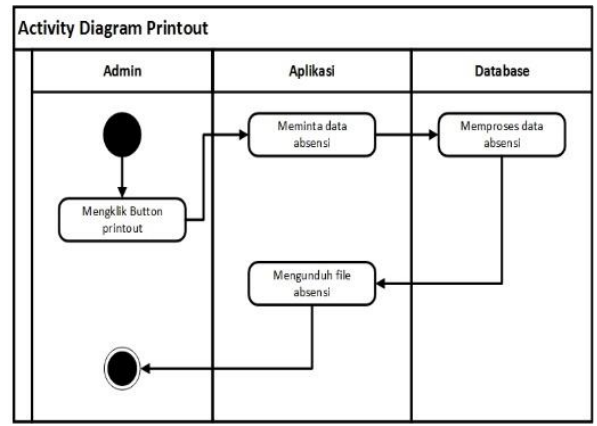

Gambar 8. Activity Diagram Printout Admin

\section{Activity Diagram Absen User}

Adapun perancangan activity diagram absen user adalah sebagai berikut

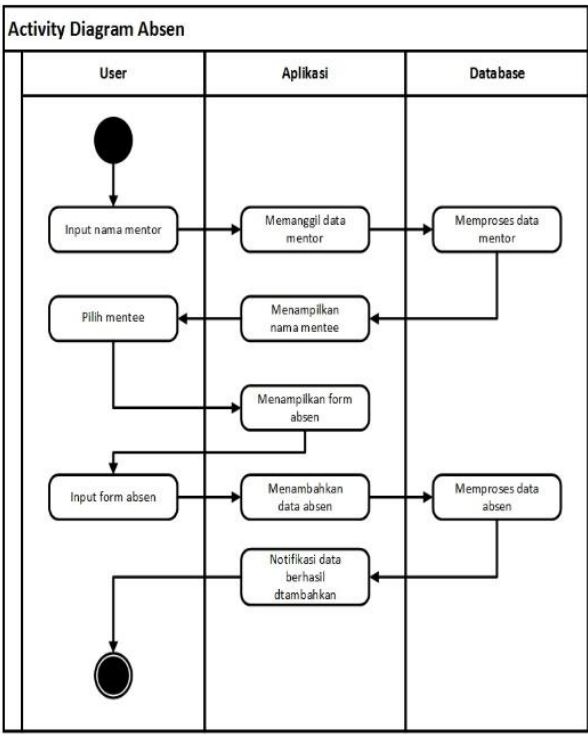

Gambar 9. Activity Diagram Absen User

\section{Activity Diagram Input Mentee User}

Adapun perancangan activity diagram input mentee user adalah sebagai berikut.

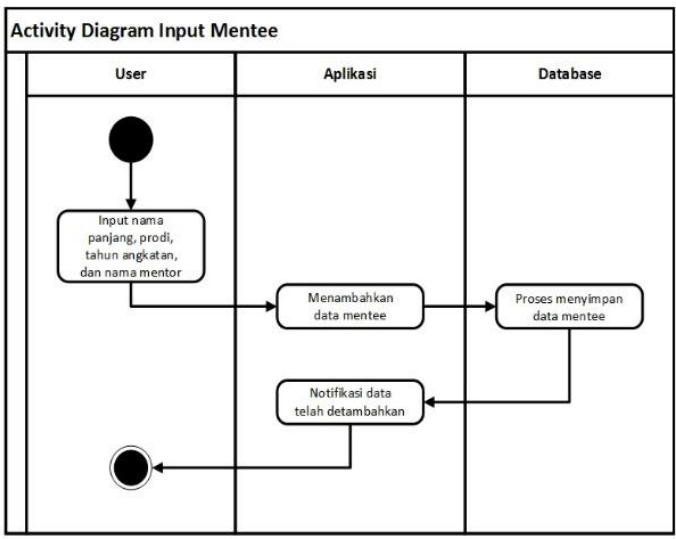

Gambar 10. Activity Diagram Input Mentee User

\section{Sequence Diagram}

Sequence Diagram pada aplikasi ini dibagi menjadi dua bagian yaitu bagian admin, dan bagian user. Setiap bagian mempunyai beberapa sequence diagram yang berfungsi untuk meng-gambarkan interaksi antar objek-objek yang ada, berikut dibawah ini adalah sequence diagram pada Aplikasi Pelaporan Kegiatan Mentoring di Unversitas Teknologi Sumbawa Berbasis Android. 


\section{Class Diagram}

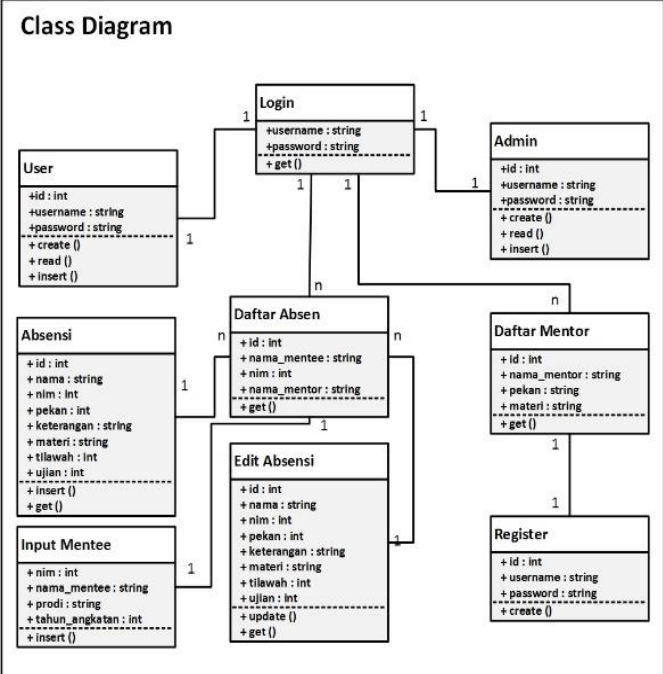

2. Sequence Diagram Daftar MentorAdmin Adapun perancangan Sequence Diagram daftar mentor admin adalah sebagai berikut.

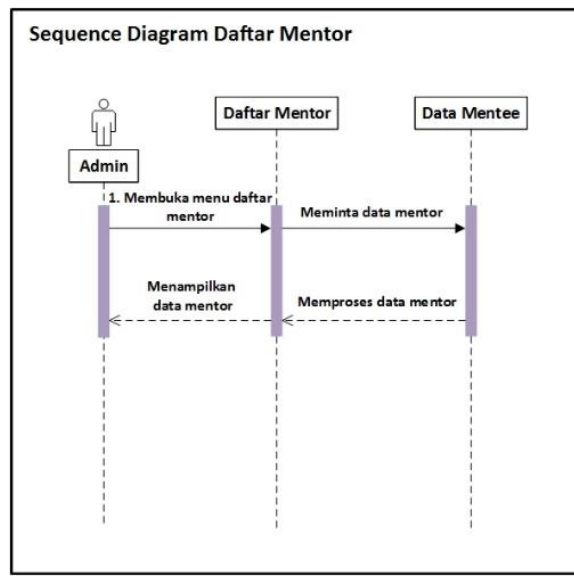

Gambar 11. Sequence Diagram Daftar MentorAdmin

3. Sequence Diagram Absen User

Adapun perancangan Sequence absen $u s e r$ adalah sebagai berikut.

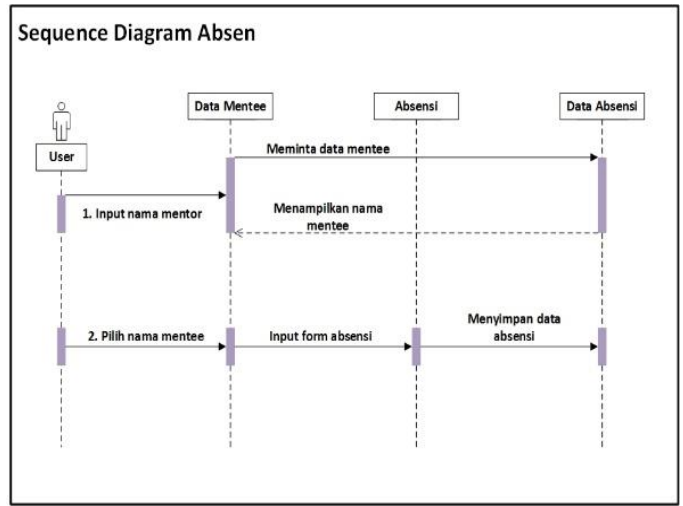

Gambar 12. Sequence Diagram Absen User
Class diagram menunjukan interaksi antar kelas dan aplikasi serta garis yang dihubungkan antar kelas menunjukan hubungan komunikasi antara class diagram. Berikut dibawah ini merupakan class diagram pada Aplikasi Pelaporan Kegiatan Mentoring di Unversitas Teknologi Sumbawa Berbasis Android.

\section{Implementasi Interface}

Adapun tampilan user interface dibagi menjadi dua bagian, yaitu bagian admin, dan bagian user. Berikut rancangan tampilan pada Aplikasi Pelaporan Kegiatan Mentoring di Unversitas Teknologi Sumbawa Berbasis Android:

\section{Impelementasi Halaman Login}

Adapun tampilan halaman login adalah sebagai berikut.

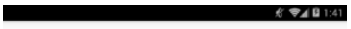

Gambar 13. Implementasi Halaman Login

Gambar diatas merupakan tampilan login setelah halaman splash screen, Pada tampilan diatas adalah tampilan implementasi dari perancangan tampilan halaman login.

\section{Implementasi Halaman Daftar Mentor Admin}

\section{Class Diagram}


Adapun perancangan tampilan halaman daftar mentor admin adalah sebagai berikut.

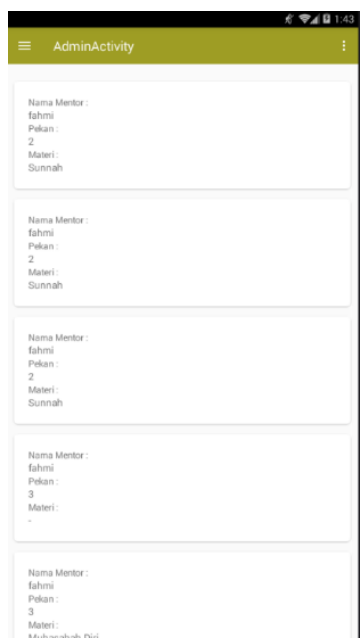

Gambar 14. Implementasi Halaman Daftar Mentor Admin

Gambar diatas merupakan tampilan halaman daftar mentor admin saat admin telah login kedalam aplikasi. Pada tampilan diatas adalah tampilan implementasi dari perancangan tampilan daftar mentor admin.

\section{Implementasi Halaman Daftar Absen User}

Adapun tampilan halaman daftar absen user adalah sebagai berikut.

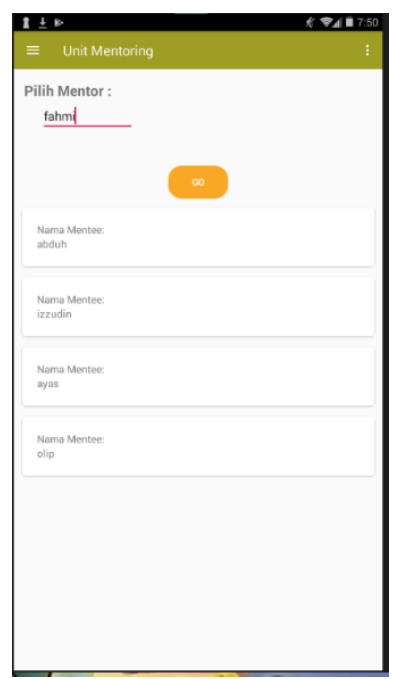

Gambar 15.Implementasi Halaman Daftar Absen User

Gambar diatas merupakan tampilan halaman daftar absen user. Pada tampilan diatas adalah tampilan implementasi dari perancangan tampilan daftar absen user.

\section{Pengujian Sistem}

Adapun hasil pengujian perangkat lunak yang dilakukan menggunakan pengujian black box testing dalam Aplikasi Pelaporan Kegiatan
Mentoring di Unversitas Teknologi Sumbawa Berbasis Android adalah sebagai berikut.

\section{Pengujian Daftar Mentor Admin}

Adapun pengujian daftar mentor admin adalah sebagai berikut.

Tabel 2. Pengujian Daftar Mentor Admin

\begin{tabular}{|c|c|c|c|}
\hline \multicolumn{4}{|c|}{ Hasil Uji } \\
\hline $\begin{array}{l}\text { Aksi } \\
\text { Actor }\end{array}$ & $\begin{array}{c}\text { Yang } \\
\text { diharapkan }\end{array}$ & pengamatan & $\begin{array}{l}\text { kesimpul } \\
\text { an }\end{array}$ \\
\hline $\begin{array}{l}\text { Login } \\
\text { sebagai } \\
\text { admin }\end{array}$ & $\begin{array}{l}\text { Menampil- } \\
\text { kan listview } \\
\text { daftar mentor } \\
\text { setelah } \\
\text { melakukan } \\
\text { proses login }\end{array}$ & $\begin{array}{l} \\
E \\
E \\
E \\
E \\
E \\
E \\
E \\
E \\
E \\
E\end{array}$ & sesuai \\
\hline
\end{tabular}

Berdasarkan tabel pengujian daftar mentor admin diatas, dapat penulis simpulkan bahwa proses menampilkan daftar mentor telah berjalan dengan baik dan sesuai dengan yang diharapkan.

\section{Pengujian Daftar Absen User}

Adapun pengujian daftar absen user adalah sebagai berikut.

Tabel 3. Pengujian Daftar Absen User

\begin{tabular}{|c|c|c|c|}
\hline \multicolumn{4}{|c|}{ Hasil Uji } \\
\hline Aksi Actor & $\begin{array}{c}\text { Yang } \\
\text { diharapka } \\
n\end{array}$ & $\begin{array}{l}\text { pengama } \\
\text { tan }\end{array}$ & kesimpulan \\
\hline $\begin{array}{l}\text { Login } \\
\text { sebagai } \\
\text { user }\end{array}$ & $\begin{array}{l}\text { Menampilk } \\
\text { an halaman } \\
\text { daftar absen }\end{array}$ & $=$ & Sesuai \\
\hline $\begin{array}{l}\text { Mengisi } \\
\text { kolom } \\
\text { mentor }\end{array}$ & $\begin{array}{l}\text { Menampilk } \\
\text { an nama- } \\
\text { nama } \\
\text { mentee }\end{array}$ & $\begin{array}{l}= \\
=- \\
=- \\
=- \\
=-\end{array}$ & Sesuai \\
\hline $\begin{array}{l}\text { Memilih } \\
\text { listview } \\
\text { nama } \\
\text { mentee }\end{array}$ & $\begin{array}{l}\text { Menampilk } \\
\text { an halaman } \\
\text { absensi }\end{array}$ & 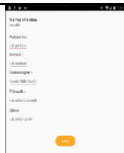 & Sesuai \\
\hline
\end{tabular}

Berdasarkan tabel pengujian daftar absen user diatas, dapat penulis simpulkan bahwa proses daftar absen user berjalan dengan baik.

\section{KESIMPULAN DAN SARAN}




\section{Kesimpulan}

Dari hasil analisis dan perancangan aplikasi yang telah dibangun, maka dapat ditarik kesimpulan bahwa Aplikasi Pelaporan Kegiatan Mentoring di Universitas Teknologi Sumbawa Berbasis Android telah selesai dibangun menggunakan Android Studio, PHP sebagai bahasa pemrograman dan database MySql. Dengan selesai dibangunnya Aplikasi Pelaporan Kegiatan Mentoring di Universitas Teknologi Sumbawa Berbasis Android ini dapat mempermudah dalam proses penginputan absensi, penilaian membaca Al-Qur'an, dan penilaian ujian yang sudah terkomputerisasi, kemudian terdapat laporan akhir kegiatan mentoring.

\section{Saran}

Dari hasil Aplikasi Pelaporan Kegiatan Mentoring di Universitas Teknologi Sumbawa Berbasis Android, penulis memberikan saran agar pada tahap selanjutnya dilakukan pengembangan dengan melakukan perhitungan nilai akhir kegiatn mentoring secara otomatis.

\section{DAFTAR PUSTAKA}

[1] Prakoso, Setiawan, (2016), Perancangan Aplikasi Pelaporan Kerusakan Prasarana Berbasis Android Menggunakan GCM (Google Cloud Messaging)(Studi Kasus: Dinas Kependudukan dan Catatan Sipil Kota Salatiga), Universitas Kristen Satya Wacana, Salatiga.

[2] Etika, Rahmawati N, (2017), Aplikasi Pelaporan Data Siswa Berbasis WEB (Studi Kasus: SDN Telukan 02 Sukohajo), Universitas Muhammadiyah Surkarta, Surakarta.

[3] Maulidiansyah, R., Rakhman, Deny F., Ramdhani, Muhammad A., 2017, Aplikasi Pelaporan Kerusakan Jalan Tol Menggunakan Web Service Berbasis Android, Jurnal Istek, Edisi Mei 2017 Volume X No.1, Jurnal Istek, Bandung.

[4] Harahap, Nazaruddin S., 2012, (Edisi Revisi). Pemrograman Aplikasi Mobile Smartphone dan Tablet PC Berbasis Android, Informatika, Bandung.

[5] Ambler, S. W., 2005, "The Elements of UML 2.0 Style", Cambridge University Press, United States of America.

[6] Sommerville, Ian., 2011, "Software Engeneering 9th Edition”, Pearson: Education Inc, America.

[7] Sukamto, Rosa Ariani, 2009, "Langkah-langkah Pengujian Perangkat dan Evaluasi Piranti Lunak”, Informatika, Bandung.

[8] Harahap, Nazaruddin S., 2012, (Edisi Revisi). Pemrograman Aplikasi Mobile Smartphone dan Tablet PC Berbasis Android, Informatika, Bandung.

[9] J. Kent Crawford, 2010, The Strategic Project Office 2nd Edition, CRC Press, USA.

[10] Raco, J.R, 2010, Metode Penelitian Kualitatif, PT Gramedia Widiasarana Indonesia, Jakarta. 